LETTER TO EDITOR

\title{
Risk of Dengue epidemics in Northern Himalayan state of India: are we prepared enough
}

\author{
Gaurav Kumar \& Shweta Pasi \\ ICMR-National Institute of Malaria Research, Sector-8, Dwarka. Delhi, India
}

\begin{abstract}
Until recently, Northern Himalayan states like Himachal Pradesh of India were free from the hold of dengue. But a new threat looms with introduction of dengue to comparatively cooler areas of the country. It has been postulated in view of climate change phenomenon that dengue will also become a major public-health threat in Himachal Pradesh in the years to come. Therefore, Assessment of impact of climate change on dengue should be undertaken which will help in quantification of additional burden of the disease and population to be affected at district level. It will also help in early preparedness for coping with the projected effect of climate change on dengue in the vulnerable hot spots. J Microbiol Infect Dis 2021; 11(1):42-43.
\end{abstract}

Keywords: Dengue; climate change; vector-borne diseases

\section{Dear Editor,}

Dengue is one of the major public health problems in India which is gripping the entire nation at a rapid pace. During the year 2017, a total of 188401 cases of dengue with 325 deaths were reported from the country [1]. The causative agent of the disease, flavivirus is transmitted to humans by the infective bite of the Aedes aegypti mosquito, the primary vector of dengue in India. Until recently, Northern Himalayan states like Himachal Pradesh were free from the hold of dengue. But since 2012, cases of dengue are being reported regularly from some of the districts of Himachal Pradesh.

Cases of dengue have risen from zero in 2011 to 4653 in 2018 in this state (Figure 1). A new threat looms with the introduction of dengue to comparatively cooler areas of the country. Factors that have been found to underlie the expansion of dengue include climate change, urbanization, globalization with increased transport, and lack of preparedness in terms of vector control facilities. Among these, climate change appears to be primarily responsible for seeding the disease in Himachal Pradesh.
As per the state report on strategy and action plan on climate change drafted in 2012, there has been a rise in temperature in the north-west Himalayan region by about $1.6{ }^{\circ} \mathrm{C}$ in the last century [2]. Higher temperatures are well-known to favor the proliferation of mosquitoes even in areas where mosquitoes were not present earlier. Not only this warm temperature also promotes several physiological activities of these insects such as host-seeking, flight range, and activity and biting. As the evidence for climate change has been documented in the context of malaria from one of the cooler Himalayan states Uttarakhand [3], it is proven that climate change is happening and therefore, there are more chances of dengue becoming a regular public health problem in Himachal Pradesh. Impacts of climate change in the context of malaria have been studied in India and it has been postulated that by the year 2030, Himachal Pradesh will be more prone to malaria [4].

As malaria and dengue both are mosquito-borne infections and the vectors of both diseases require similar conditions of temperature and relative humidity for their development (i.e. $28{ }^{\circ} \mathrm{C}$ and $60 \% \mathrm{RH})$, the same model can be 
hypothesized even in the context of dengue. Therefore, it can be rightly assumed that akin to malaria, dengue will also become a major public-health threat in Himachal Pradesh in the years to come.

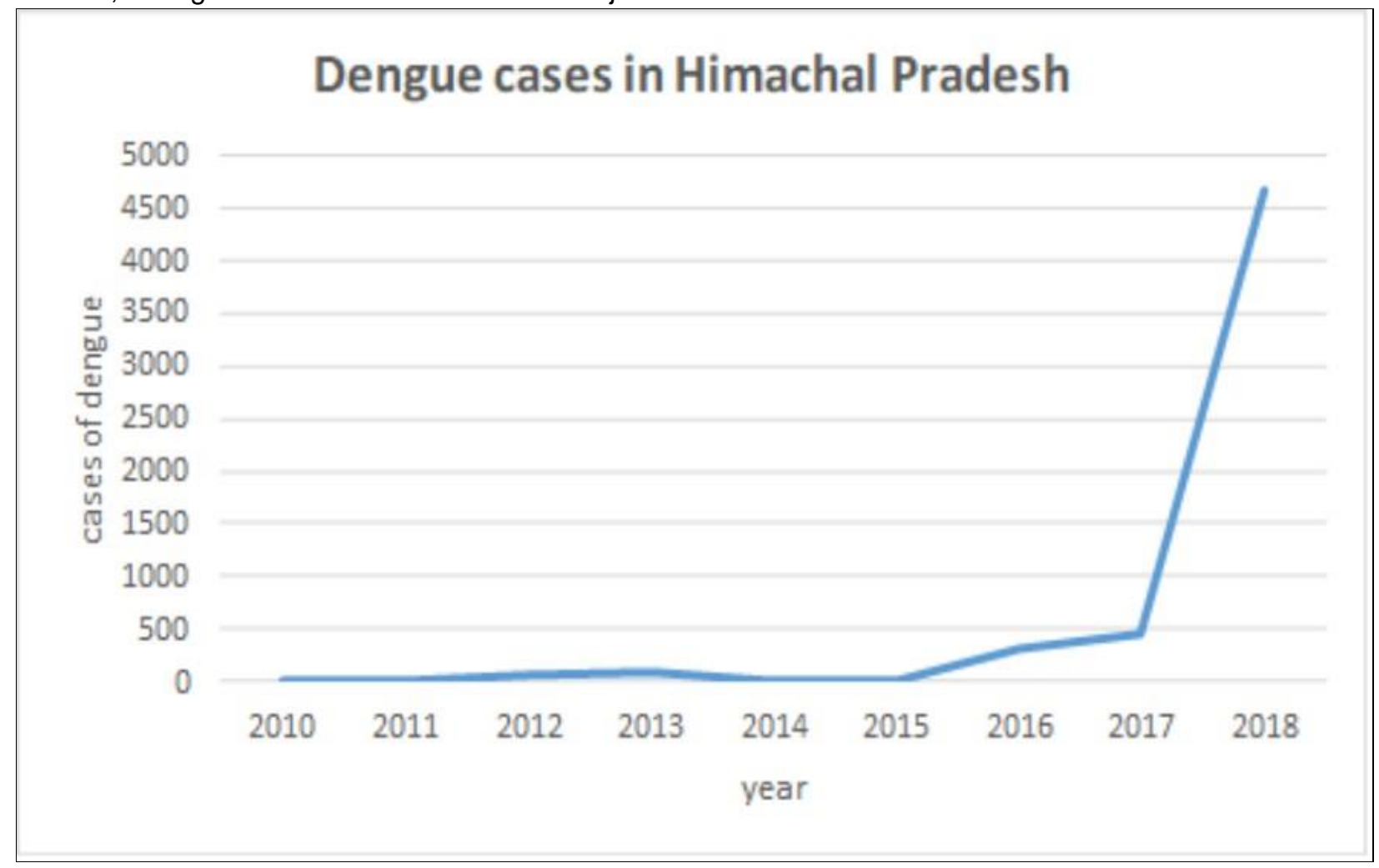

Figure 1. Annual trend of dengue in Himachal Pradesh.

In the wake of recent outbreaks in Himachal Pradesh, it is of utmost importance that vulnerability assessment and adaptive measures should be prioritized in regions that are presently free from disease, particularly in the Himalayan belt. Further, dissemination of knowledge on disease occurrence, preventive methods and personal protection, etc. should be carried out on an urgent basis following situation analysis [5]. Baseline studies to know the current adaptive capacity of the community towards climate change in the context of dengue are also warranted so as to mitigate the possible impacts. Assessment of the impact of climate change on dengue should be undertaken which will help in the quantification of the additional burden of the disease and population to be affected at the district level. It will also help in early preparedness for coping with the projected effect of climate change on dengue in vulnerable hot spots.

Correspondence: Dr. Shweta Pasi, ICMR-

National Institute of Malaria Research, Sector-8, Dwarka. Delhi, India
Email: shweta.pasi@gmail.com

\section{ACKNOWLEDGMENTS}

Acknowledgment: Authors are thankful to the Director, ICMR-National Institute of Malaria Research, Delhi for providing the necessary facilities.

Financial Support: This study was performed without any financial support.

Conflict of interest: The authors have declared no conflicts of interest.

\section{REFERENCES}

1. Dengue/DHF situation in India, 2019, www.nvbdcp.gov.in (accessed on 16 April 2019).

2. State strategy and action plan on climate change Himachal Pradesh 2012, http://moef.gov.in/wpcontent/uploads/2017/08/Himachal-Pradesh.pdf (accessed on 2.9.19).

3. Dhiman RC, Yadav YK, Saraswat S, Singh P. Altitude, temperature, and malaria vectors in Nainital and Udham Singh Nagar districts of Uttarakhand, India: An evidence-based study. J Vector Borne Dis. 2013; 50(3): 220-224. 
4. Dhiman RC, Chavan L, Pant M, Pahwa S. National and regional impacts of climate change on malaria by 2030. Current Science 2011; 101 (3): 372-383.

5. Dhiman RC, Pahwa S, Dhillon GPS, Dash AP. Climate change and threat of vector borne diseases in India: are we prepared? Parasitol Res 2010; 106:763-773. 